\title{
How the Medical Culture Contributes to Coworker-Perpetrated Harassment and Abuse of Family Physicians
}

\author{
Baukje Miedema, $P b D^{1}$ \\ Leslie MacIntyre, MSC ${ }^{1}$ \\ Sue Tatemichi, $M D^{1}$ \\ Anita Lambert-Lanning, MLS 2 \\ Francine Lemire, $M D^{2}$ \\ Donna Manca, MD \\ Vivian Ramsden, $P b D^{4}$ \\ 'Dalhousie University Family Medicine \\ Teaching Unit, Fredericton, Canada \\ ${ }^{2}$ College of Family Physician of Canada \\ Mississauga, Ontario, Canada \\ ${ }^{3}$ Department of Family Medicine, Univer- \\ sity of Alberta, Edmonton, Alberta, Canada \\ ${ }^{4}$ Department of Family Medicine, \\ University of Saskatchewan, Saskatoon, \\ SK, Canada

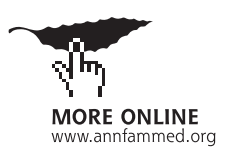

Conflicts of interest: authors report none.

\section{CORRESPONDING AUTHOR}

Baukje Miedema, PhD

Dalhousie University Family Medicine

Teaching Unit

700 Priestman St

Fredericton, NB

E3B 5N5, Canada

Baukje.miedema@horizonNB.ca

\begin{abstract}
PURPOSE Harassment and abuse in the workplace of family physicians has been associated with higher levels of stress, increased consumption of alcohol, and higher risk for developing mental health problems. Few studies have examined issues contributing to abusive encounters in the workplace of family physicians.

METHODS For the overall study we used a mixed methods design, which included a cross-sectional survey of a randomly selected sample of active family physicians from the database of the College of Family Physicians of Canada and telephone interviews with those who reported experiencing work related harassment and abuse in the last year. The data presented here arise from the qualitative interviews of the study, which were analyzed thematically.
\end{abstract}

RESULTS The interview arm of the study included 23 female and 14 male participants. The major themes that emerged from the study were (1) modeling of abusive behaviors, (2) status hierarchy among various medical disciplines, (3) shortage of physicians, and (4) lack of transparent policies and follow-up procedures after abusive encounters. The results are discussed using the broken window theory.

CONCLUSION Many family physicians experience harassing and abusive encounters during their training or in the workplace. The current medical culture appears to contribute to harassment and abuse in the workplace of family physicians in Canada. We described the components that intentionally or unintentionally facilitate abusive behavior in the medical culture.

Ann Fam Med 2012;10:111-117. doi:10.1370/afm.1341.

\section{INTRODUCTION}

$\mathrm{H}$

ealth care workers are at greater risk of workplace abuse than most other workers, with the exception of law enforcement officers and taxi drivers. ${ }^{1}$ Among health care professionals, nurses and family physicians are at greatest risk for being abused. ${ }^{2-6}$ Research conducted in Canada, Japan, Australia, New Zealand, and the United States has found that in their work, physicians experience many forms of harassment and abuse, ${ }^{1}$ including verbal abuse, intimidation, sexual harassment, stalking, and assault from both patients and colleagues. ${ }^{7-10}$ An Australian study reported that $64 \%$ of general practitioners reported abuse in the previous year, with low-level mistreatment, such as verbal abuse, being the most common. More than $10 \%$ reported experiences of sexual harassment and physical abuse. ${ }^{7}$ Similar trends have been found in such other countries as New Zealand and Canada. ${ }^{8,11}$

Research conducted in Canada, carried out by our research team, reported that $98 \%$ of family physicians reported having experienced at least 1 minor abusive event (eg, humiliation), 75\% reported having experienced a major event (eg, sexual harassment), and 39\% had experienced a 
severe event (eg, assault) during their career as a physician. ${ }^{9}$ Twenty-nine percent of the polled physicians reported having been abused in the previous month by either a patient or family member of a patient. A small group reported having been abused by colleagues (9\%) and coworkers $(6 \%)$ in the previous month.

Some physicians may be more at risk for abuse than others. For instance, physicians working in emergency departments, psychiatric emergency departments, and after-hours clinics, as well as those on house calls, have an increased likelihood of experiencing abusive encounters. ${ }^{7,12-15}$ Emergency departments appear to be especially problematic. An American study reported that 1 in 3 emergency department physicians was physically assaulted during the previous year. ${ }^{13}$ Additionally, psychiatrists and physicians whose practices include large numbers of patients with mental illness and addiction problems are at higher risk of encountering abuse., , 15-17 $^{-17}$

Abuse in the workplace has been associated with experiencing higher levels of stress, increased consumption of alcohol, and an increased risk for developing mental health difficulties, including depression, anxiety, and suicidal ideation, as well as absence from work, physical problems, employment termination, and compromised patient care. ${ }^{18-25}$ Abusive encounters in the workplace may lead to post-traumatic stress disorder, attrition of workers, and physician refusal to work in such high-risk areas as emergency departments and after-hours clinics. 5,8,12,21

Hershcovis and Barling argue that negative outcomes regarding workplace abuse will be strongest when the "perpetrator is a supervisor [or] coworker," and the "weakest effects" are when the perpetrator is an outsider (patient or their family members). ${ }^{26,27}$ Several studies have indicated that verbal abuse perpetrated by colleagues and coworkers is generational. ${ }^{28-41}$ Surgical residents reported that belittlement, intimidation, and harassment were perceived to be motivational tools for the profession. ${ }^{28}$ Some supervisors described feeling justified in perpetuating belittlement of residents because they themselves had been treated in a similar fashion during their training. Thus it appears that abusive interactions may be embedded in the broader medical culture. $^{42-45}$ The objective of our overall research was to document the prevalence, the monthly incidence rates, and the impact of abuse in the workplace of family physicians in Canada. This article is based on the qualitative data focusing on the experiences of the family physicians who were harassed or abused by coworkers.

\section{METHODS}

This report is based on a larger mixed methods study. ${ }^{9,10}$ A random sample of practicing family physicians across
Canada who were members of the College of Family Physicians of Canada (CFPC) were mailed a survey package that contained questionnaire and a card with a request for an interview with participants who had experienced work-related abuse in the past 12 months. The completed questionnaire and the request for interview card were returned to 2 separate study addresses, and the questionnaires and interviews were not linked.

The purpose of the interview was to explore the experience of abuse in greater detail. ${ }^{46}$ An interview guide was developed by the research team based on the literature and questionnaire data (see the Supplemental Appendix, available at http://www.annfammed. org/content/10/2/111/suppl/DC1). As a means of preserving the privacy of the participants, we asked few questions regarding social demographic data.

Once a survey respondent indicated his or her willingness to participate in an interview, a consent form was forwarded to the potential participant. The participants could either return the signed consent to the study center or give oral consent before commencing the telephone interview. Permission to audiorecord the telephone interview was explicitly sought, and the interviewer signed a document to indicate that the proper steps to obtain oral consent had been followed. Financial compensation was not offered for participation. The interviews were conducted in either English or French according to the preference of the interviewee, and the interviewers and participants were paired by sex. Female physicians were interviewed either by the principal investigator or 1 of 2 experienced female research assistants, whereas male physicians were interviewed by an experienced male research assistant. The interviews were transcribed verbatim and then translated to English for coding. Ethical approval for the study was granted in 2008 by the Research Ethics Boards from Dalhousie University (2008-1817), the University of Alberta (6-040808) and the University of Saskatchewan (08-244).

The data were analyzed thematically from the common patterns that emerged from physicians' disclosures. ${ }^{46}$ This process began with a team meeting during which all team members and 2 research assistants read the same 3 transcripts. The agreed-upon themes and subthemes were organized and then moved into higher levels of abstractions. Two research assistants thematically coded the remaining transcripts using the group consensus coding scheme. We used the qualitative data analysis program NVivo (QSR International Pty Ltd) to organize the themes and categories. ${ }^{12,21}$

Our research team consisted of 6 members: a sociologist (B.M.), a CFPC network representative (A.L.L.), an academic family physician (D.M.), ${ }^{47,48}$ a participatory research methods specialist (V.R.), a practicing family 
physician (S.T.), and an executive member of the CFPC (F.L.). In addition, the project employed 4 research assistants to assist with survey mailings, telephone interviews, and transcript coding.

\section{RESULTS}

Of the 3,802 questionnaires mailed, 770 survey respondents returned usable questionnaires, and 41 indicated a willingness to be interviewed. Ultimately, 37 telephone interviews were completed with 23 female and 14 male physicians, of whom 4 were French speaking and 33 were English speaking. All audio recordings were transcribed verbatim. Two participants did not consent to have their interview audio-recorded, so detailed notes were taken. ${ }^{46}$

In the interviews 10 different types of perpetrators were described. The most commonly described perpetrators were patients and family members of patients (45 times); colleagues, such as family physicians, specialists, supervisors, and administrators (39 times); and others (13 times). ${ }^{2}$ Although the survey data indicated that most perpetrators were patients or their family members, and the interview participants mentioned patient-related abuse, they spoke at much greater length about colleague-related (including supervisor and administrator) abuse, thus indicating the lasting impact of in-group abuse and prompting our focus on how the medical culture may contribute (intentionally or unintentionally) to maltreatment among colleagues and coworkers.

To put our findings into context and understand the results of this qualitative component of the study, we draw upon the criminology-based broken window theory. This theory asserts that when lesser criminal acts, such as broken windows, are tolerated, more vandalism and other types of crime will eventually occur in the community. ${ }^{51-53}$ Hesketh at al argue that when emotional abuse, such as humiliation and harassment, is tolerated in the workplace, it will eventually lead to more aggressive and violent behavior. ${ }^{54}$ We use a model that illustrates how various broken windows in the medical culture may predispose family physicians to abuse. To create a culture that does not intentionally or unintentionally facilitate abuse, these 4 broken windows must be repaired (Figure 1).

For the rest of this article, we use the term abuse to refer to all types of abuse, including harassment. Abusive incidents were not mutually exclusive and included verbal abuse, physical threat, and intimidation, as well as sexual harassment. Four major themes emerged from the data that showed how the medical culture contributes to the facilitation and perpetuation of abuse in the workplace of family physicians.

Quotes from English interviews will be denoted using $\mathrm{F}$ for female and $\mathrm{M}$ for male, whereas quotes from interviews conducted with French female physicians will be denoted as FF and French male physicians as MF.

\section{Modeling Harassing and Abusive Behavior}

Several participants reported that abusive behavior is regularly modeled in the workplace, and this modeling contributes to abuse being perpetuated from generation to generation. One participant reported that abusive behavior starts in medical school. She said:

It [abuse] was...more common in medical school... I was at [medical school X] and, I mean, humiliation is part of the way they teach (F15).

What follows is the description by another participant who recalled an incident that took place during her residency training on an overnight shift in the Emergency Department. She reported that when she called her preceptor, he seemed to be inebriated and used racial slurs. She said:

So that's when I hung up on him, and I told the nurse in emergency that I was not going to continue the night with him, being on call, because somebody who calls me that, I can't call him back for the rest of the consultations (F8).

Shortly after, the preceptor arrived in the Emergency Department while still intoxicated. She said:

..then I heard him coming to the emergency yelling, and when I opened the door I saw him taking the chart and 
throwing it towards a nurse. And she had to move her head so she wouldn't get hit by the chart.... You know, rather, I didn't sleep, I was pale, I was shaking (F8).

Even after medical training has been completed, abuse in the work setting continues. One participant reported that abusive comments and actions were an everyday occurrence. She said:

Primarily you learn by example and by working with other physicians and, you know they're always putting each other down. Really, abuse is there every day all the time, because people are always saying negative things about each other (F21).

\section{Professional Hierarchy}

Another theme that emerged from the data was the belief that there is a professional hierarchy within the medical community in which specialists are highly valued and family physicians less so. Different pay schedules and scales were cited as important factors in the perpetuation of professional hierarchies. ${ }^{4}$ One participant described the following:

When we are "on call" for surgery, we are "on call" [all] night... but we are not paid [unless we are providing services]. When a specialist does the same work, they are paid to be "on call" (FF12).

Residency training was also singled out for abuse related to hierarchy. One male described his experiences:

I think when you're in a teaching hospital, part of teaching training is to say, you know, if you're smarter than the next person, if you're a more senior resident than the next person, you're supposed to shit on the person below you (M6).

\section{Shortage of Physicians}

The shortage of physicians was also identified as an important factor contributing to abusive experiences within the medical system. Participants reported feeling pressured to work longer shifts. A participant working in an Emergency Department illustrated the impact of this shortage. He said:

It's a very, very subtle ... abuse. You can't point to any one person and say: "You are abusing me." But rather, it's a systemic abuse. Look, there's not enough of us. [There are] too many people who need things. We just gotta keep going... (M5).

A female physician, who works regularly as a locum tenens in areas with a severe shortage of physicians, encountered a lot of patients during one work week. She was not able to see them all during her rotation. The next locum tenens was very upset when she transferred the patients to him. She said:
When I transferred the patients, he was really unhappy that he had so many patients. So then he started to yell, he was really, really angry and aggressive, and he talked like it was my fault that there were so many patients... (FF18).

\section{Lack of Policies and Follow-up Procedures}

Participants who reported being adversely affected by harassing or abusive experiences identified several issues with policies and follow-up procedures that they perceived as contributing to these events. Although many hospitals have written policies for dealing with abuse issues, participants described barriers to the implementation of these policies. One male participant said:

Administration claims to have all sorts of policies, but when I was polling the people I work with and the nurses and the emerg[ency] docs, nobody's ever seen a policy, nobody's ever seen administration involved with this. We're not feeling particularly supported by the administration (M8).

Private practices often lacked policies to effectively deal with abuse altogether. Even clinics with a zero tolerance policy sometimes lack formal policies or reporting procedures. One male physician said:

You know, I don't think it's ever been written down, but you know, I don't tolerate anything physical, obviously. I mean, if someone were to get up and shove me, ... I mean that will end a relationship that we have immediately (M12).

Participants working across a variety of settings who did report abusive experiences to supervisors believed little was done after such reporting. Senior colleagues and administrative staff were described as unwilling to deal with abusive encounters regardless of the perpetrator. A participant described a sense of indifference from her managers. She said:

This person has said inappropriate sexual remarks...to female residents, as well as female nursing staff, and they've actually reported them to me. I have actually reported [these incidents]...to two fairly high senior staff people. [H]er response was simply, she shrugged her shoulder and said: "Ooh that's too bad." Another...senior [supervisor] said: "Well this person is socially immature, just accept it" (F3).

\section{DISCUSSION}

More women than men participated in the qualitative component of this study, which is consistent with other qualitative studies. ${ }^{49,50}$ It is possible that women are more comfortable telling their stories, even though both male and female physicians were equally victimized. ${ }^{9}$

The modeling of abusive behavior often starts in medical school and repeats itself from one generation of physicians to the next. Hesketh et al argue that 
although humiliation and psychological abuse may not seem serious, if it is tolerated, it may set a negative example, and an increasing number of people may engage in such behavior. ${ }^{54}$ If a small broken window is not fixed, more windows may be vandalized, so that the consequences of even minor abuse may be severe.

Professional hierarchies between specialists and family physicians are not uncommon and have been previously documented. ${ }^{55}$ The tension between family physicians and specialists seems to be multifactorial and includes a considerable difference in remuneration between these groups, as well as a certain mutual disrespect. ${ }^{56}$ In addition, the hierarchy in residency training, resulting sometimes in abuse, has been consistently documented in the literature. ${ }^{18,19,28}$

Abuse in the workplace appears to be exacerbated when family physicians feel overworked. Family physicians in Canada average 50 hours of work per week (apart from on-call duties). ${ }^{57}$ Undoubtedly the nationwide shortage of physicians (and therefore large medical practices) does little to ameliorate the problem of long work hours. ${ }^{58}$ The physician shortage broken window runs deep in the system. Several strategies are needed to decrease workload. One such strategy may be the use of other health professionals in practices, such as nurse practitioners and physician assistants, to assist in the management of certain patients, such as patients with chronic conditions. ${ }^{59-61}$

Many participants felt that they were not supported when they reported having been abused. If institutions have such policies, few participants were aware of their existence or how to access them. The literature is scant on this issue. Most policies seem to relate to sexual harassment and not to other types of abuse. ${ }^{62}$

The culture of abuse in the family physicians' workplace may be perpetuated through the modeling of abuse starting in medical school, moving through residency and into the daily workplace of family physicians. It may be further exacerbated by the "lowly" position of the family physician in the medical hierarchy and the stress brought on by the shortage of family physicians in the workplace, and it may persist as a result of the lack of institutional support for victims and lack of accountability for perpetrators. An approach to eliminating the problem is needed, because abuse has serious consequences for the victims, including physical and psychological symptoms and reduced job satisfaction. ${ }^{63}$

We believe that to address this culture of abuse, medical schools and residency training programs should include in their curriculum how to deal with coworker and patient abuse. Residents need to know the impact of abuse and how to deal with it when it occurs. There are no Canadian studies and few international studies that have examined the experiences of family medicine residents to date. In short, the best place to fix the broken windows is during training.

Our study had limitations. To enhance the trustworthiness of the data, only participants who had experienced abuse were interviewed. Participants were self-selected volunteers. Hence, the study results may not be generalizable to the larger population. No corroborating evidence was requested regarding the severity, intensity, and the impact of the abusive event.

At present, little is being undertaken to address the issue of abuse in the workplace of family physicians. The most worrisome finding from our study is that these kinds of practices are a part of the medical culture starting in medical school and carried out throughout medical training and into the work environment. This culture is supported by power imbalances, power structures, and such systemic issues as physician shortages. The criminological broken window theory is helpful to explain why abuse may be perpetuated in the medical system, and it also provides a context for an approach to address the issue.

It is clear that effective elimination of abuse must start from efforts that begin on the first day of medical school and continue through residency training and into clinical practice. Clinician educators must themselves be educated about the effect that abuse can have on learners and must look to their own approaches to teaching and amend these as necessary. Learners and clinicians must function in an environment that is intolerant of abuse; they must have readily available avenues for the reporting and rectifying of abusive situations and resources for personal healing.

The current medical culture has left these windows broken. Finding a solution for the existing human resource crisis throughout the country requires a different approach that involves a political solution and is beyond the scope of individual clinicians and medical schools but that ought to be championed by our medical societies and colleges.

To read or post commentaries in response to this article, see it online at http://www.annfammed.org/content/10/2/111.

Key words: workplace; abuse reporting; organizational culture; qualitative research

Submitted April 23, 2011; submitted, revised, August 16, 2011; accepted August 30, 2011.

Funding support: This research was supported by a grant from the Canadian Institutes for Health Research grant MOP-86475.

Previous presentation: Portions of this report has been presented at the Interprofessional Health Research Conference, March 25, 2011, Saint John, New Brusnwick, Canada.

Acknowledgment: We would like to thank Dr Ryan Hamilton for reviewing the revised manuscript. 


\section{References}

1. Canadian Centre for Occupational Health and Safety. Violence in the Workplace. 2007. http://www.ccohs.ca/oshanswers/psychosocial/ violence.html. Accessed Mar 9, 2009.

2. Arnetz JE, Arnetz BB, Söderman E. Violence toward health care workers. Prevalence and incidence at a large, regional hospital in Sweden. AAOHN J. 1998;46(3):107-114.

3. Henderson AD. Nurses and workplace violence: nurses' experiences of verbal and physical abuse at work. Nurs Leadersh (Tor Ont). 2003;16(4):82-98.

4. Walsh A. Our white coats are not armour. Protecting physicians in the doctor-patient relationship. Can Fam Physician. 2005;51:1604-1605.

5. King LA, Mclnerney PA. Hospital workplace experiences of registered nurses that have contributed to their resignation in the Durban metropolitan area. Curationis. 2006;29(4):70-81.

6. Duncan SM, Hyndman K, Estabrooks CA, et al. Nurses' experience of violence in Alberta and British Columbia hospitals. Can J Nurs Res. 2001;32(4):57-78.

7. Magin PJ, Adams J, Ireland M, Heaney S, Darab S. After hours care-a qualitative study of GPs' perceptions of risk of violence and effect on service provision. Aust Fam Physician. 2005;34(1-2):91-92.

8. Gale C, Arroll B, Coverdale J. Aggressive acts by patients against general practitioners in New Zealand: one-year prevalence. $N$ Z Med J. 2006;119(1237):U2050.

9. Miedema B, Hamilton R, Lambert-Lanning A, et al. Prevalence of abusive encounters in the workplace of family physicians: a minor, major, or severe problem? Can Fam Physician. 2010;56(3):e101-e108

10. Miedema B, Hamilton R, Tatemichi SR, et al. Monthly incidence rates of abusive encounters for Canadian family physicians by patients and their families. Int J Fam Med. 2010; doi:10.1155/2010/387202.

11. Phillips SP, Schneider MS. Sexual harassment of female doctors by patients. N Engl J Med. 1993;329(26):1936-1939.

12. Fernandes CM, Bouthillette F, Raboud JM, et al. Violence in the emergency department: a survey of health care workers. CMAJ. 1999;161(10):1245-1248.

13. Kowalenko T, Walters BL, Khare RK, Compton S; Michigan College of Emergency Physicians Workplace Violence Task Force. Workplace violence: a survey of emergency physicians in the state of Michigan Ann Emerg Med. 2005;46(2):142-147.

14. Erdos BZ, Hughes DH. Emergency psychiatry: a review of assaults by patients against staff at psychiatric emergency centers. Psychiatr Serv. 2001;52(9):1175-1177.

15. Galeazzi GM, Elkins K, Curci P. The stalking of mental health professionals by patients. Psychiatr Serv. 2005;56(2):137-138

16. Madden DJ, Lion JR, Penna MW. Assaults on psychiatrists by patients. Am J Psychiatry. 1976;133(4):422-425.

17. Antonius D, Fuchs $L$, Herbert F, et al. Psychiatric assessment of aggressive patients: a violent attack on a resident. Am J Psychiatry. 2010;167(3):253-259.

18. Frank E, Carrera JS, Stratton T, Bickel J, Nora LM. Experiences of belittlement and harassment and their correlates among medical students in the United States: Iongitudinal survey. BMJ. 2006;333 (7570):682.

19. Daugherty SR, Baldwin DC Jr, Rowley BD. Learning, satisfaction, and mistreatment during medical internship: a national survey of working conditions. JAMA. 1998;279(15):1194-1199.

20. Magin PJ, Adams J, Ireland M, Joy E, Heaney S, Darab S. The response of general practitioners to the threat of violence in their practices: results from a qualitative study. Fam Pract. 2006;23(3): 273-278.

21. Magin PJ, Adams J, Sibbritt DW, Joy E, Ireland MC. Experiences of occupational violence in Australian urban general practice: a crosssectional study of GPs. Med J Aust. 2005;183(7):352-356.
22. Kaukiainen A, Salmivalli C, Bjorkqvist K, et al. Overt and covert aggression in work settings in relation to the subjective well-being of employees. Aggress Behav. 2001;27(5):360-371.

23. Gerberich SG, Church TR, McGovern PM, et al. An epidemiological study of the magnitude and consequences of work related violence: the Minnesota Nurses' Study. Occup Environ Med. 2004;61(6):495-503.

24. Zahid MA, Al-Sahlawi KS, Shahid AA, Awadh JA, Abu-Shammah H Violence against doctors: 2. Effects of violence on doctors working in accident and emergency departments. Eur J Emerg Med. 1999; 6(4):305-309.

25. Ahmed I, Banu H, Al-Fageer R, Al-Suwaidi R. Cognitive emotions: depression and anxiety in medical students and staff. J Crit Care. 2009;24(3):e1-e7.

26. Hershcovis MS, Barling J. Towards a multi-foci approach to workplace aggression: a meta-analytic review of outcomes from different perpetrators. J Organ Behav. 2010;31(1):22-44.

27. Miedema B, Tatemichi SR, Hamilton R, et al. Effect of colleague and coworker abuse on family physicians in Canada. Can Fam Physician. 2011;57(12):1424-1431.

28. Musselman LJ, MacRae HM, Reznick RK, Lingard LA. 'You learn better under the gun': intimidation and harassment in surgical education. Med Educ. 2005;39(9):926-934.

29. Jacobs CD, Bergen MR, Korn D. Impact of a program to diminish gender insensitivity and sexual harassment at a medical school. Acad Med. 2000;75(5):464-469.

30. Quine L. Workplace bullying in junior doctors: questionnaire survey. BMJ. 2002;324(7342):878-879.

31. Baldwin DC Jr, Daugherty SR, Rowley BD. Residents' and medical students' reports of sexual harassment and discrimination. Acad Med. 1996;71(10)(Suppl):S25-S27.

32. Mangus RS, Hawkins CE, Miller MJ. Prevalence of harassment and discrimination among 1996 medical school graduates: a survey of eight US schools. JAMA. 1998;280(9):851-853.

33. Frank E, Brogan D, Schiffman M. Prevalence and correlates of harassment among US women physicians. Arch Intern Med. 1998; 158(4):352-358.

34. Baldwin DC Jr, Daugherty SR. Do residents also feel "abused"? Perceived mistreatment during internship. Acad Med. 1997;72(10) (Suppl 1):S51-S53.

35. Cook DJ, Liutkus JF, Risdon CL, Griffith LE, Guyatt GH, Walter SD. Residents' experiences of abuse, discrimination and sexual harassment during residency training. McMaster University Residency Training Programs. CMAJ. 1996;154(11):1657-1665.

36. vanlneveld CH, Cook DJ, Kane SL, King D; The Internal Medicine Program Directors of Canada. Discrimination and abuse in internal medicine residency. J Gen Intern Med. 1996;11(7):401-405.

37. Cook DJ, Griffith LE, Cohen M, Guyatt GH, O’Brien B. Discrimination and abuse experienced by general internists in Canada. J Gen Intern Med. 1995;10(10):565-572.

38. Uhari M, Kokkonen J, Nuutinen $\mathrm{M}$, et al. Medical student abuse: an international phenomenon. JAMA. 1994;271(13):1049-1051.

39. Wolf TM, Randall HM, von Almen K, Tynes LL. Perceived mistreatment and attitude change by graduating medical students: a retrospective study. Med Educ. 1991;25(3):182-190.

40. Sheehan KH, Sheehan DV, White K, Leibowitz A, Baldwin DC Jr. A pilot study of medical student 'abuse'. Student perceptions of mistreatment and misconduct in medical school. JAMA. 1990;263(4): 533-537.

41. White GE. Sexual harassment during medical training: the perceptions of medical students at a university medical school in Australia. Med Educ. 2000;34(12):980-986.

42. Myers MF. Abuse of residents: it's time to take action. CMAJ. 1996; 154(11):1705-1708. 
43. Kassebaum DG, Cutler ER. On the culture of student abuse in medical school. Acad Med. 1998;73(11):1149-1158.

44. Rautio A, Sunnari V, Nuutinen M, Laitala M. Mistreatment of university students most common during medical studies. BMC Med Educ. 2005;5:36.

45. Lempp $\mathrm{H}$, Seale $\mathrm{C}$. The hidden curriculum in undergraduate medical education: qualitative study of medical students' perceptions of teaching. BMJ. 2004;329(7469):770-773.

46. Creswell JW. Research Design: Qualitative, Quantitative, and Mixed Methods Approaches. 2nd ed. Thousand Oaks, CA: Sage Publications Inc; 2003.

47. Manca DP. Woman physician stalked. Personal reflection and suggested approach. Can Fam Physician. 2005;51:1640-1645.

48. Manca D. What doctors won't say: they're living in fear. Globe and Mail. 2005 February 15.

49. De Koninck $M$, Bergeron $P$, Bourbonnais R. Women physicians in Quebec. Soc Sci Med. 1997;44(12):1825-1832.

50. Malterud K, Hollnagel $\mathrm{H}$. The doctor who cried: a qualitative study about the doctor's vulnerability. Ann Fam Med. 2005;3(4):348-352.

51. Kelling G, Wilson J. Broken windows. The Atlantic. 1982.

52. Keizer K, Lindenberg S, Steg L. The spreading of disorder. Science. 2008;322(5908):1681-1685.

53. Kelling G. How New York became safe: the full story. City Journal. 2011.

54. Hesketh KL, Duncan SM, Estabrooks CA, et al. Workplace violence in Alberta and British Columbia hospitals. Health Policy. 2003;63(3): $311-321$.
55. Manca D, Varnhagen S, Brett-MacLean P, Allan GM, Szafran O. Respect from specialists: concerns of family physicians. Can Fam Physician. 2008;54:1434-1435, 5 e1-5.

56. Berendsen AJ, Kuiken A, Benneker WH, Meyboom-de Jong B, Voorn TB, Schuling J. How do general practitioners and specialists value their mutual communication? A survey. BMC Health Serv Res. 2009;9:143.

57. College of Family Physicians of Canada, Canadian Medical Association, The Royal College of Physicians and Surgeons of Canada, Canadian Institute for Health Information. National physician survey [question 18]. http://www.nationalphysiciansurvey.ca/nps/2010_ Survey/methods/pdf/en/NPS2010fpgp-e.pdf.

58. Viviers S, Lachance L, Maranda MF, Ménard C. Burnout, psychological distress, and overwork: the case of Quebec's ophthalmologists. Can J Ophthalmol. 2008;43(5):535-546.

59. Ashton CW, Aiken A, Duffie D. Physician Assistants-a solution to wait times in Canada? Health Manag Forum. 2007;20(2):38-42.

60. Dove N. Can international medical graduates help solve Canada's shortage of rural physicians? Can J Rural Med. 2009;14(3):120-123.

61. Collier R. Doctors call for plan to curb physician shortage. (MAJ. 2008;178(4):384.

62. American Academy of Pediatrics. Committee on Pediatric Workforce. Prevention of sexual harassment in the workplace and educational settings. Pediatrics. 2006;118(4):1752-1756.

63. Aquino K, Thau S. Workplace victimization: aggression from the target's perspective. Ann Rev Psycho. 2009;60(1):717-714. 